\title{
Patient, Surgery, and Hospital Related Risk Factors for Surgical Site Infections following Total Hip Arthroplasty
}

\author{
Georgios Triantafyllopoulos, ${ }^{1}$ Ottokar Stundner, ${ }^{2}$ \\ Stavros Memtsoudis, ${ }^{3}$ and Lazaros A. Poultsides ${ }^{1}$ \\ ${ }^{1}$ Department of Orthopaedic Surgery, Division of Adult Reconstruction and Joint Replacement, Hospital for Special Surgery, \\ Weill Medical College of Cornell University, 535 East 70th Street, New York, NY 10021, USA \\ ${ }^{2}$ Department of Anesthesiology, Perioperative Medicine and Intensive Care Medicine, Paracelsus Medical University, \\ Muellner Hauptstrasse 48, 5020 Salzburg, Austria \\ ${ }^{3}$ Department of Anesthesiology, Hospital for Special Surgery, Weill Medical College of Cornell University, 535 East 70th Street, \\ New York, NY 10021, USA
}

Correspondence should be addressed to Georgios Triantafyllopoulos; triantafyllopoulosg@hss.edu

Received 18 September 2014; Accepted 1 January 2015

Academic Editor: Ali Hosseini

Copyright (C) 2015 Georgios Triantafyllopoulos et al. This is an open access article distributed under the Creative Commons Attribution License, which permits unrestricted use, distribution, and reproduction in any medium, provided the original work is properly cited.

\begin{abstract}
Surgical site infections (SSI) following total hip arthroplasty (THA) have a significantly adverse impact on patient outcomes and pose a great challenge to the treating surgeon. Therefore, timely recognition of those patients at risk for this complication is very important, as it allows for adopting measures to reduce this risk. This review discusses literature reported risk factors for SSI after THA. These can be classified into patient-related factors (age, gender, obesity, comorbidities, history of infection, primary diagnosis, and socioeconomic profile), surgery-related factors (allogeneic blood transfusion, DVT prophylaxis and coagulopathy, duration of surgery, antibiotic prophylaxis, bearing surface and fixation, bilateral procedures, NNIS index score, and anesthesia type), and hospital-related factors (duration of hospitalization, institution and surgeon volume, and admission from a healthcare facility). All these factors are discussed with respect to potential measures that can be taken to reduce their effect and consequently the overall risk for infection.
\end{abstract}

\section{Introduction}

The success of total hip arthroplasty (THA) in relieving pain and improving function in patients with end-stage degenerative or inflammatory arthritis of the hip is undisputed. The number of procedures per year is estimated to further rise in the next years, as even younger patients with hip arthritis are expected to seek surgical treatment. Kurtz et al. [1] recently reported that, by the year 2020 , the projected number of THAs per year will exceed 500,000. Periprosthetic joint infection (PJI) remains a devastating complication after THA, as its treatment may involve multiple surgical interventions and long-term administration of antibiotics and is associated with poor patient satisfaction and increased socioeconomic costs $[2,3]$. PJI is also correlated with increased mortality, particularly in the group of elderly patients [4]. The rate of surgical site infection (SSI) has been reported to range from $0.2 \%$ during hospitalization to $1.1 \%$ up to 5 years after surgery [5]. Therefore, the projected increase in the number of THA will also reflect a respective increase in the absolute number of patients presenting with this complication.

Measures including perioperative antibiotics, exhaust suits, laminar air flow operating rooms, ultraviolet lighting, and antibiotic-impregnated cement have been introduced in an attempt to control infection rates after joint replacement surgery. However, before treating a patient with arthritis, it is very important that surgeons are able to identify potential risk factors for developing an infection. The purpose of this review is to summarize those risk factors predisposing to SSI following THA. 


\section{Search Strategy and Selection Criteria}

An unrestricted computerized search of MEDLINE and OVID SP for studies published in the English language between 1990 and 2014 was conducted. The following terms were used in various combinations: "total hip arthroplasty," "risk factors," "infected joint arthroplasties," "surgical site infection," "periprosthetic joint infection," "prosthesis-related infection," "joint replacement infections," "musculoskeletal wound infections," and "osteomyelitis." Abstracts were reviewed and studies reporting on risk factors for superficial or deep PJI following THA were selected for full text review.

\section{Patient-Related Factors}

3.1. Age and Gender. The risk for infection after THA has been found to be higher in older patients [6-8]. In comparison to the younger population, these patients are usually characterized by impaired immune response to infectious agents, inferior nutritional status, and possibly more comorbidities. On the other hand, other investigators have determined younger age as a risk factor for infection after total joint arthroplasty [9]. In another study [10], the same association between younger age and infection risk was found for total knee arthroplasty but not for THA. The higher odds for future revision surgery related with younger patients has been proposed as an explanation of the increased infection risk in this population [9].

Male gender has been also reported as an independent risk factor for infection after THA [10-13]. Higher activity levels increase the risk for subsequent revision surgery, and also gender differences in skin microbial colonization [13] might account for this effect. In contrast to this, other studies showed an association for increased infection risk with female gender $[6,14]$.

3.2. Obesity. As obesity is considered a contemporary pandemic and its association with degenerative joint disease is known [15], obese patients present very frequently for THA. Nonetheless, morbidly obese patients undergoing THA have been found to have significantly higher rates of complications compared to nonobese patients, within 5 years postoperatively [16]. A more specific correlation between obesity and a higher risk for SSI after THA has been reported by several investigators $[7,9,14,17-26]$. It has been shown that a $\mathrm{BMI} \geq$ 35 is associated with a higher risk for positive intraoperative cultures during THA [26]. Furthermore, morbid obesity has been correlated with prolonged wound drainage [27], which is a known risk factor for deep SSI $[8,28]$. Treating morbid obesity before THA can be therefore beneficial to patients not only from a general health perspective, but also in terms of reducing the risk of developing a postprocedural SSI. Diet and lifestyle modifications, pharmaceutical interventions, psychological support, and even bariatric surgery can be considered in these patients. This requires a multidisciplinary approach, involving the collaboration between the treating surgeon and a clinical dietician, an internist, a psychiatrist, and a bariatric surgeon. However, even with these measures, it is very unlikely that an obese patient scheduled to undergo
THA will achieve such a preoperative weight loss that can have an effect on the risk for infection. It appears that a substantial preoperative weight-loss before surgery is needed for a significant effect to take place [29].

3.3. Comorbidities. The American Society of Anesthesiologists (ASA) score reflects the impact of existing comorbidities on the patient's general health status. An ASA score equal to or more than 3 has been determined by some investigators as an independent risk factor for SSI after THA [6, 14, 30]. Other studies have found an association between an increased risk for infection and the presence of more than 2 comorbidities $[20,24,31]$, with each additional comorbidity significantly increasing this risk [31]. A Charlson comorbidity index of more than 5 has been also determined as an independent risk factor for PJI [12].

It is well established that, in patients undergoing surgery, diabetes mellitus (DM) is associated with increased risk for complications and increased length of hospital stay [32]. In the perioperative period, optimal glycemic control can be a challenge, as surgical stress in addition to modifications of the patient's usual diet needs to be taken into account. In general, hyperglycemia may cause disruption of the host's physiologic response to a bacterial load [33]. Diabetes has been identified as an independent risk factor for developing SSI after total joint arthroplasty, including THA [7, 9, 24, 31, $34,35]$. Even in patients without a diagnosis of DM, a fasting blood glucose of $>140 \mathrm{mg} / \mathrm{dL}$ has been associated with a 3 -fold increase in the risk of infection [24]. HbA1c is used to provide an estimate of the average blood glucose concentrations for a period expanding to 3 months before testing $[32,36]$. However, its importance in predicting the risk for infection after total joint arthroplasty has not been confirmed [35]. Recognition of those patients with uncontrolled DM or even with perioperative fluctuations of the blood glucose levels is thus very important. In addition to interventions aiming to reduce bacterial load (e.g., use of antibiotic-impregnated cement), close monitoring of patients' perioperative blood glucose levels, and control of hyperglycemia (e.g., insulin sliding scale) can help minimize the risk of infection.

Connective tissue disease has been also correlated with increased risk for PJI after THA [11, 19, 37]. This group of conditions, including rheumatoid arthritis (RA), systemic lupus erythematosus, and psoriatic arthritis, is associated with modulation of the patient's immune system, resulting in predisposition to infection. Patients with longer duration of RA are at increased risk [38]. Moreover, these patients often receive chronic immunosuppressive treatment. Chronic glucocorticoid treatment has been identified as a risk factor for infection after THA $[8,18]$. Novel biologic agents (TNFa blockers) used in the treatment of many of these conditions are known to adversely affect the patient's ability to fight infection and their use has been identified as a risk factor for PJI following total joint arthroplasty $[38,39]$. It has been reported that patients with RA that have never received TNFa blockers have lower rates of bacteremia than those patients under biologic treatment [39]. Interruption of TNFa blockers before surgery has been advocated [38, 40]; however, 
other studies have failed to prove that this measure actually decreases the infection risk [41].

The presence of malignancy has been confirmed to increase PJI risk $[8,10,42]$. It remains unclear, however, whether this correlation is due to the potential effects of malignancy on the immune response to infection per se or to the associated treatment such patients receive, which frequently consists of chronic administration of glucocorticoids and cytotoxic agents [42].

A number of other comorbidities have been also described as independent contributors to the infection risk after THA. These include preoperative anemia [19], liver disease $[8,10,43]$, alcohol $[7,8]$ and intravenous drug abuse [8], previous myocardial infarction [24, 25], congestive heart failure $[10,24]$, postoperative atrial fibrillation [25], renal insufficiency [24,25], fluid and electrolyte disorders [10], and pulmonary circulatory disease [10].

3.4. History of Infection and Staphylococcus aureus Colonization. It has been supported that infection involving the superficial layers of the surgical site is an independent risk factor for subsequent deep PJI $[8,18,42]$. Furthermore, increased drain output has been correlated with superficial infection and therefore with indirectly elevated risk for deep infection following THA $[18,27]$. Prolonged wound drainage and other signs of superficial infection should alert the treating surgeon and prompt to further diagnostic testing and management [8]. It should be noted that, even though a direct association between the use of drains and the risk for SSI after THA has not been proven [13], it is recommended that drains should be removed in a timely fashion [44].

Patients with previous PJI of the same or different site have been recognized to be at increased risk for an ensuing infection [37, 45]. However, this effect is not attributed to the multiple number of artificial joints, but rather to contamination from surgery or to patients' poor general health status and immunocompromise [45].

Despite the fact that direct contamination of the wound during surgery seems to be the primary pathogenetic mechanism, especially with regard to Staphylococcus aureus and Staphylococcus epidermidis, bacteremia related with the presence of infection at sites other than joints may also lead to hematogenous seeding of a prosthetic joint and development of PJI in a considerable percentage of patients [46]. Patients with THA and infections of the skin [8], respiratory [8], or urinary tract $[8,25]$, as well as dental $[47]$ and abdominal infections [8], were found to be at increased risk for PJI. The bacterial load seems to play a critical role in this effect [48]. Asymptomatic bacteriuria has been also determined as a risk factor for infection with gram negative bacteria following THA [49]. Therefore, an aggressive treatment protocol and close monitoring of patients undergoing THA and an infection at another site is warranted.

Colonization with Staphylococcus aureus, when combined with other variables including active tobacco use and BMI $\geq 30 \mathrm{~kg} / \mathrm{m}^{2}$, has been identified as a risk factor for infection after THA [23]. Similarly, other investigators have found that colonization or prior infection with Staphylococcus aureus as remotely as 10 years before presentation increases the risk for SSI after total joint arthroplasty [50]. Moreover, patients colonized with methicillin-resistant Staphylococcus aureus (MRSA) are known to be at increased risk for SSI after elective orthopaedic surgery [51, 52]. For these patients, the use of vancomycin for perioperative prophylaxis is advocated, as it is related with reduced infection rates [53].

3.5. Primary Diagnosis. Patients subjected to THA for posttraumatic osteoarthritis have been found to be at increased risk for infection [8]. In addition, higher rates of PJI have been reported in patients that underwent THA for traumatic hip injury (e.g., hip fracture) [6, 11,34]. The local effects of a traumatic injury (hematoma formation, tissue necrosis, etc.), as well as its systemic consequences, may account for this correlation [6]. Dislocation, associated with local trauma and often requiring multiple reoperations, is another risk factor reported [8]. Analysis of the data retrieved from the Nordic Arthroplasty Register Association revealed that avascular necrosis of the femoral head was also correlated with increased risk for PJI [11]. Finally, several studies have indicated revision surgery $[23,34,37]$ or prior joint arthroplasty [42] as an independent risk factor for developing infection following THA.

3.6. Socioeconomic Factors. Lower socioeconomic status, as indicated with entitlement to public assistance for Medicare, has been correlated with the risk of PJI [12]. Moreover, minority race has been also determined as an independent risk factor for SSI [10]. An increased risk for infection following THA has been also described for patients living in rural areas [7]. Poor living conditions, comorbidities, failure to adequately follow medical instructions, and delay in seeking help may predispose all these patients to increased infection risk.

\section{Surgery-Related Factors}

4.1. Allogeneic Blood Transfusion. Several studies have pointed out allogeneic blood transfusion as an independent risk factor for SSI after total joint arthroplasty, including THA [17, 25, 54, 55]. Transfusion of allogeneic blood is considered to induce immunomodulation to the recipient, due to the presence of white blood cells (WBC) above a critical level [56]. However, even transfusion of WBC-filtered allogeneic blood has been found to independently increase the risk of infection after THA [54]. Preoperative autologous blood donation, regional anesthesia [57], and prevention of excessive intraoperative blood loss can reduce the need for allogeneic blood transfusion [58] and therefore the risk of developing SSI.

4.2. DVT Prophylaxis and Coagulopathy. It has been reported that patients receiving low molecular weight heparin (LMWH) for DVT prophylaxis have significantly more prolonged wound drainage [27]. This has been attributed to the faster onset of action of LMWH in comparison to Coumadin. Nonetheless, aggressive anticoagulation both 
with warfarin and with heparin has been identified as an independent risk factor for SSI [17, 59, 60]. Thus, DVT prophylactic medications should be closely monitored during the early postoperative period and any adverse events, including prolonged drainage and hematoma formation, should be recognized and addressed in a timely fashion. Coagulopathy has been also correlated with an increased SSI risk $[10,19]$. Coagulopathy can be the result of a wide spectrum of disorders, including those inherited (e.g., hemophilia) and those acquired (e.g., liver disease). However, in most cases, appropriate pharmacologic interventions can maintain the coagulation mechanism on a level that may permit surgery while minimizing the risk for complications.

4.3. Prolonged Duration of Surgery. Several studies have identified prolonged operating time as an independent risk factor for PJI of the hip $[6,8,12,13,23,24,30,34,37]$. Procedures requiring more time usually relate to complex cases and may involve extensile exposures and considerable tissue damage [6]. Dealing with issues such as suboptimal surgeon training, inadequate preoperative planning, and substandard cooperation of operating room staff may lead to improvement of surgical times and therefore contribute to the decrease of the infection risk [23].

4.4. Antibiotic Prophylaxis and Skin Preparation. Antibiotic prophylaxis is a well-established measure to control postoperative infections. Failure to adhere to protocols of prophylactic antibiotic administration, both in terms of dosing and timing, has been associated with increased risk for PJI in patients undergoing THA $[8,30]$. Additionally, for cemented implants, the use of plain cement (i.e., nonimpregnated with antibiotics) has been correlated with increased risk for revision due to infection [11]. Finally, although a recent international consensus meeting on periprosthetic joint infections did not acknowledge any differences between different agents [61] and in contrast to previous data [62], in one study skin preparation with chlorhexidine was found to be associated with increased rates of superficial wound infection when compared to povidone iodine [17].

4.5. Bearing Surface and Fixation Type. An increased infection risk has been linked with the use of metal-on-metal bearings in THA [63]. Metallosis-related local soft-tissue damage and increased rates of revision associated with this type of implants may be contributing factors. Moreover, in a study of arthroplasty register data, hybrid fixation was identified as a risk factor for revision of a THA due to infection [11]. However, the authors suggested that this effect might be due to confounding factors not recorded in the register.

4.6. Bilateral Procedures. Bilateral THA has been associated with an increased risk for infection in some studies [14, 25]. It is therefore recommended that bilateral procedures should be reserved for patients without major comorbidities [25]. Nonetheless, as other researchers have supported the safety of this treatment modality $[64,65]$, further investigation of the role of bilateral procedures is warranted.

4.7. National Nosocomial Infections Surveillance (NNIS) Index Score. The NNIS index score reflects the patient's general health (as related to the ASA score) but also takes into account the procedure's duration and the condition of the surgical wound. A NNIS index score equal to or more than 1 has been identified as an independent risk factor for PJI [42].

4.8. Anesthesia. In recent years, a number of publications have suggested that the choice of regional versus general anesthesia may have a profound influence on the general and possibly the local infection risk in orthopedic patients $[57,66$, 67]. Possible mechanisms suggested by various authors are beneficial effects of neuraxial anesthesia on tissue perfusion, immune function, and blood loss. While the effect on shortterm outcomes is increasingly well documented, long-term outcome data are rare at this time.

Other aspects of anesthesia may also play a role in preventing SSI after THA. For example, given the effectiveness of intraoperative high $\mathrm{FiO}_{2}$ in preventing SSI in the general surgery population [68], the value of implementing such strategies in the field of elective orthopaedic surgery, including THA, needs to be further clarified. Additionally, controlled epidural hypotension has been shown to significantly reduce blood loss and improve tissue perfusion through vasodilatation. As hematoma formation and need for blood transfusion have been linked to increased risk of infection, hypotension may actually be beneficial. Care has to be taken however to not equate hypotension with hypo perfusion, which may be more likely during episodes of hypovolemia due to blood loss or general anesthetic effects.

\section{Hospital-Related Factors}

5.1. Duration of Hospitalization. Patients undergoing THA were found to have an increased risk for developing PJI if their hospitalization was prolonged $[25,42]$. Similarly, non-same day surgery has been identified as an independent risk factor for PJI [23]. Hence, it is suggested that patient admission for an elective procedure such as THA should be avoided prior to the day of surgery, as longer hospitalization predisposes patients to greater exposure to nosocomial bacteria [25].

5.2. Hospital and Surgeon Volume of Procedures. Higher infection rates have been associated with low institution volume of THA procedures $[69,70]$. It is likely that highvolume institutions have organized SSI control departments and strictly adhere to measures for prevention and early detection of infections. Additionally, low surgeon volume is another variable identified as a risk factor for SSI after THA $[70,71]$. The number of cases surgeons perform seems to be conversely related to the duration of surgery and therefore may have an impact to the infection risk as well.

5.3. Admission from a Healthcare Facility. Patients admitted for THA from a healthcare facility have been found to have 
TABLE 1: Studies of risk factors for surgical site infection in patients undergoing total hip arthroplasty (THA).

\begin{tabular}{|c|c|c|c|}
\hline Study & Type & Number of THAs & Risk factors identified \\
\hline Berbari et al. [42] & Retrospective & 526 & $\begin{array}{l}\text { Superficial surgical site infection, NNIS index score } \geq 1 \text {, } \\
\text { malignancy, prior arthroplasty. }\end{array}$ \\
\hline Bongartz et al. [37] & Retrospective & 328 & $\begin{array}{l}\text { Revision surgery, prolonged duration of surgery, previous } \\
\text { joint infection, and rheumatoid arthritis. }\end{array}$ \\
\hline Bozic et al. [19] & Retrospective & 40,919 & $\begin{array}{l}\text { Obesity, rheumatologic disease, coagulopathy, and } \\
\text { preoperative anemia. }\end{array}$ \\
\hline Bozic et al. [63] & Retrospective & $\begin{array}{l}\text { 57,047 THAs with different } \\
\text { bearing surfaces }\end{array}$ & Metal-on-metal bearing surfaces. \\
\hline Carroll et al. [17] & Retrospective & 453 & $\begin{array}{l}\text { Obesity, allogeneic blood transfusion, coagulation with } \\
\text { warfarin, and surgical skin preparation with } 0.5 \% \\
\text { chlorhexidine in } 70 \% \text { alcohol. }\end{array}$ \\
\hline Choong et al. [20] & Retrospective & 819 & Obesity and presence of $>2$ comorbidities. \\
\hline $\begin{array}{l}\text { Cordero-Ampuero } \\
\text { and de Dios [8] }\end{array}$ & Retrospective & 47 & $\begin{array}{l}\text { Older age, systemic corticosteroid treatment, prolonged } \\
\text { duration of surgery, trauma, malignancy, liver disease, } \\
\text { alcohol abuse, IV drug abuse, inadequate antibiotic } \\
\text { prophylaxis, persistent wound secretion, dislocation, skin } \\
\text { infection, urinary tract infection, abdominal infection, } \\
\text { and pneumonia. }\end{array}$ \\
\hline Dale et al. [11] & Retrospective & 432,168 & $\begin{array}{l}\text { Trauma, male gender, hybrid fixation, cement without } \\
\text { antibiotics, inflammatory arthritis, and avascular necrosis. }\end{array}$ \\
\hline $\begin{array}{l}\text { Dowsey and Choong } \\
{[21]}\end{array}$ & Retrospective & 1,207 & Obesity. \\
\hline Font-Vizcarra et al. [26] & Prospective & 402 & $\mathrm{BMI} \geq 35$ \\
\hline Friedman et al. [22] & Retrospective & 12,355 & Obesity. \\
\hline Geubbels et al. [69] & Prospective & $\begin{array}{c}\text { 13,608 THAs and } \\
\text { hemiarthroplasties }\end{array}$ & Low annual institution volume. \\
\hline Gilson et al. [39] & Retrospective & $\begin{array}{l}22 \text { patients receiving TNFa } \\
\text { blockers subjected to hip, knee, } \\
\text { shoulder, and ankle arthroplasty }\end{array}$ & Treatment with TNFa blockers. \\
\hline Smith et al. [53] & Prospective & 308 THAs and TKAs & Allogeneic WBC-filtered blood transfusion. \\
\hline Iorio et al. [35] & Retrospective & 1,659 & Diabetes. \\
\hline Jafari et al. [45] & Retrospective & 55 THAs and TKAs & Previous joint infection. \\
\hline Jiang et al. [43] & Retrospective & 878 THAs & Liver cirrhosis. \\
\hline Katz et al. [70] & Retrospective & 58,521 & Low institution volume and low surgeon volume. \\
\hline Lai et al. [31] & Retrospective & 22 & Diabetes and presence of $>2$ comorbidities. \\
\hline Lee et al. [72] & Retrospective & 74 & Admission from a healthcare facility. \\
\hline Malinzak et al. [9] & Retrospective & 2,775 & Younger age, diabetes, and obesity. \\
\hline Maoz et al. [23] & Retrospective & $\begin{array}{l}3,672 \text { primary THAs, } 406 \\
\text { revision THAs }\end{array}$ & $\begin{array}{l}\text { Obesity, revision surgery, prolonged duration of surgery, } \\
\text { and non-same day surgery. }\end{array}$ \\
\hline McDougall et al. [59] & Retrospective & 1,047 & Anticoagulation with warfarin or IV heparin. \\
\hline Momohara et al. [38] & Retrospective & 81 & $\begin{array}{l}\text { Treatment with TNFa blockers and longer duration of } \\
\text { rheumatoid arthritis. }\end{array}$ \\
\hline Mraovic et al. [24] & Retrospective & $\begin{array}{l}101 \text { THAs and TKAs versus } 1,847 \\
\text { controls }\end{array}$ & $\begin{array}{l}\text { Diabetes, obesity, prolonged duration of surgery, presence } \\
\text { of }>2 \text { comorbidities, history of myocardial infarction, } \\
\text { congestive heart failure, and renal insufficiency. }\end{array}$ \\
\hline Muilwijk et al. [71] & Retrospective & 15,906 & Low surgeon volume. \\
\hline Namba et al. [14] & Retrospective & 30,491 & Obesity, female gender, ASA score $\geq 3$, and bilateral THAs. \\
\hline Newman et al. [55] & Retrospective & 1,622 & Allogeneic blood transfusion. \\
\hline Ong et al. [12] & Retrospective & 39,929 & $\begin{array}{l}\text { Prolonged duration of surgery, Charlson index }>5 \text {, male } \\
\text { gender, and lower socioeconomic status. }\end{array}$ \\
\hline Parvizi et al. [60] & Retrospective & 35 & INR $>1.5$ \\
\hline
\end{tabular}


TABle 1: Continued.

\begin{tabular}{|c|c|c|c|}
\hline Study & Type & Number of THAs & Risk factors identified \\
\hline Patel et al. [27] & Retrospective & 1,221 & $\begin{array}{l}\text { Obesity, coagulation with LMWH, and increased drain } \\
\text { tube loss. }\end{array}$ \\
\hline Peel et al. [18] & Prospective & 36 & $\begin{array}{l}\text { Obesity, superficial surgical site infection, increased drain } \\
\text { tube loss, and systemic corticosteroid treatment. }\end{array}$ \\
\hline Poultsides et al. [10] & Retrospective & 412,356 & $\begin{array}{l}\text { Malignancy, coagulopathy, liver disease, male gender, } \\
\text { congestive heart failure, fluid and electrolyte disorders, } \\
\text { pulmonary circulatory disease, and minority race. }\end{array}$ \\
\hline Pulido et al. [25] & Retrospective & 5,060 & $\begin{array}{l}\text { Obesity, allogeneic blood transfusion, urinary tract } \\
\text { infection, history of myocardial infarction, renal } \\
\text { insufficiency, bilateral THAs, postoperative atrial } \\
\text { fibrillation, and prolonged hospitalization. }\end{array}$ \\
\hline Ridgeway et al. [6] & Prospective & $\begin{array}{l}16,291 \text { primary THAs, } 2,550 \\
\text { revision THAs }\end{array}$ & $\begin{array}{l}\text { Older age, prolonged duration of surgery, trauma, and } \\
\text { ASA score } \geq 3 \text {. }\end{array}$ \\
\hline Saleh et al. [28] & Prospective & 33 THAs and TKAs & Hematoma formation and persistent drainage. \\
\hline Song et al. [34] & Retrospective & 3,422 & $\begin{array}{l}\text { Diabetes, revision surgery, prolonged duration of surgery, } \\
\text { and trauma. }\end{array}$ \\
\hline Sousa et al. [49] & Prospective & 1,248 THAs & Asymptomatic bacteriuria. \\
\hline van Kasteren et al. [30] & Prospective & 1,922 & $\begin{array}{l}\text { Prolonged duration of surgery, ASA score } \geq 3 \text {, and } \\
\text { administration of prophylactic antibiotics after incision. }\end{array}$ \\
\hline Willis-Owen et al. [13] & Prospective & 1,750 & Male gender and prolonged duration of surgery. \\
\hline Wu et al. [7] & Retrospective & 198 & $\begin{array}{l}\text { Older age, diabetes, obesity, alcohol abuse, and rural } \\
\text { residence. }\end{array}$ \\
\hline
\end{tabular}

increased risk for developing SSI [72]. These patients have generally inferior health status than home-residing patients and are likely to be more prone to infections.

\section{Conclusions}

Identification of risk factors for SSI in patients undergoing THA allows for implementing measures to tackle those variables that can be modified and therefore to reduce the relevant infection risk. These measures may include adequate perioperative glycemic control, adjustment of the DVT prophylactic regimen to the needs of each individual patient and close monitoring of the coagulation status, increased awareness for early signs of superficial infection, both surgeon and patient education, stringent protocols of perioperative antimicrobial prophylaxis, and so forth. It should be noted that most studies reporting on the aforementioned risk factors are of retrospective nature, yielding lower quality evidence (Table 1). On the other hand, conducting prospective studies on this field can be very difficult, given the low prevalence of PJI after THA. Moreover, many series have determined certain independent risk factors, while others have failed to confirm the role of the same variables in increasing the infection risk (Table 1). One should be therefore very careful in interpreting the results of these studies. Further investigation with higher-quality trials is warranted, in order to formulate evidence-based guidelines for managing patients with risk factors for infection, scheduled to undergo THA.

\section{Conflict of Interests}

The authors declare that there is no conflict of interests regarding the publication of this paper.

\section{References}

[1] S. M. Kurtz, K. L. Ong, E. Lau, and K. J. Bozic, "Impact of the economic downturn on total joint replacement demand in the United States: updated projections to 2021," The Journal of Bone and Joint Surgery-American Volume, vol. 96, no. 8, pp. 624630, 2014.

[2] K. J. Bozic, S. M. Kurtz, E. Lau et al., "The epidemiology of revision total knee arthroplasty in the united states," Clinical Orthopaedics and Related Research, vol. 468, no. 1, pp. 45-51, 2010.

[3] J. D. Whitehouse, N. Deborah Friedman, K. B. Kirkland, W. J. Richardson, and D. J. Sexton, "The impact of surgicalsite infections following orthopedic surgery at a community hospital and a university hospital: adverse quality of life, excess length of stay, and extra cost," Infection Control and Hospital Epidemiology, vol. 23, no. 4, pp. 183-189, 2002.

[4] S. A. McGarry, J. J. Engemann, K. Schmader, D. J. Sexton, and K. S. Kaye, "Surgical-site infection due to Staphylococcus aureus among elderly patients: mortality, duration of hospitalization, and cost," Infection Control and Hospital Epidemiology, vol. 25, no. 6, pp. 461-467, 2004.

[5] D. M. Urquhart, F. S. Hanna, S. L. Brennan et al., "Incidence and risk factors for deep surgical site infection after primary total hip arthroplasty: a systematic review," Journal of Arthroplasty, vol. 25, no. 8, pp. 1216.e3-1222.e3, 2010. 
[6] S. Ridgeway, J. Wilson, A. Charlet, G. Katafos, A. Pearson, and R. Coello, "Infection of the surgical site after arthroplasty of the hip," The Journal of Bone and Joint Surgery. British Volume, vol. 87, no. 6, pp. 844-850, 2005.

[7] C. Wu, X. Qu, F. Liu, H. Li, Y. Mao, and Z. Zhu, "Risk factors for periprosthetic joint infection after total hip arthroplasty and total knee arthroplasty in Chinese patients," PLoS ONE, vol. 9, no. 4, Article ID e95300, 2014.

[8] J. Cordero-Ampuero and M. de Dios, "What are the risk factors for infection in hemiarthroplasties and total hip arthroplasties?" Clinical Orthopaedics and Related Research, vol. 468, no. 12, pp. 3268-3277, 2010.

[9] R. A. Malinzak, M. A. Ritter, M. E. Berend, J. B. Meding, E. M. Olberding, and K. E. Davis, "Morbidly obese, diabetic, younger, and unilateral joint arthroplasty patients have elevated total joint arthroplasty infection rates," Journal of Arthroplasty, vol. 24, no. 6, supplement, pp. 84-88, 2009.

[10] L. A. Poultsides, Y. Ma, A. G. Della Valle, Y.-L. Chiu, T. P. Sculco, and S. G. Memtsoudis, "In-hospital surgical site infections after primary hip and knee arthroplasty-incidence and risk factors," Journal of Arthroplasty, vol. 28, no. 3, pp. 385-389, 2013.

[11] H. Dale, A. M. Fenstad, G. Hallan et al., "Increasing risk of prosthetic joint infection after total hip arthroplasty," Acta Orthopaedica, vol. 83, no. 5, pp. 449-458, 2012.

[12] K. L. Ong, S. M. Kurtz, E. Lau, K. J. Bozic, D. J. Berry, and J. Parvizi, "Prosthetic joint infection risk after total hip arthroplasty in the medicare population," Journal of Arthroplasty, vol. 24, supplement 6, pp. 105-109, 2009.

[13] C. A. Willis-Owen, A. Konyves, and D. K. Martin, "Factors affecting the incidence of infection in hip and knee replacement: an analysis of 5277 cases," Journal of Bone and Joint SurgerySeries B, vol. 92, no. 8, pp. 1128-1133, 2010.

[14] R. S. Namba, M. C. S. Inacio, and E. W. Paxton, "Risk factors associated with surgical site infection in 30491 primary total hip replacements," The Journal of Bone and Joint Surgery-British Volume, vol. 94, no. 10, pp. 1330-1338, 2012.

[15] C. Cooper, H. Inskip, P. Croft et al., "Individual risk factors for hip osteoarthritis: obesity, hip injury, and physical activity," The American Journal of Epidemiology, vol. 147, no. 6, pp. 516-522, 1998.

[16] Y. H. Chee, K. H. Teoh, B. M. Sabnis, J. A. Ballantyne, and I. J. Brenkel, "Total hip replacement in morbidly obese patients with osteoarthritis: results of a prospectively matched study," The Journal of Bone and Joint Surgery-British Volume, vol. 92, no. 8, pp. 1066-1071, 2010.

[17] K. Carroll, M. Dowsey, P. Choong, and T. Peel, "Risk factors for superficial wound complications in hip and knee arthroplasty," Clinical Microbiology and Infection, vol. 20, no. 2, pp. 130-135, 2014.

[18] T. N. Peel, M. M. Dowsey, J. R. Daffy, P. A. Stanley, P. F. M. Choong, and K. L. Buising, "Risk factors for prosthetic hip and knee infections according to arthroplasty site," The Journal of Hospital Infection, vol. 79, no. 2, pp. 129-133, 2011.

[19] K. J. Bozic, E. Lau, S. Kurtz et al., "Patient-related risk factors for periprosthetic joint infection and postoperative mortality following total hip arthroplasty in medicare patients," Journal of Bone and Joint Surgery-Series A, vol. 94, no. 9, pp. 794-800, 2012.

[20] P. F. M. Choong, M. M. Dowsey, D. Carr, J. Daffy, and P. Stanley, "Risk factors associated with acute hip prosthetic joint infections and outcome of treatment with a rifampinbased regimen," Acta Orthopaedica, vol. 78, no. 6, pp. 755-765, 2007.
[21] M. M. Dowsey and P. F. M. Choong, "Obesity is a major risk factor for prosthetic infection after primary hip arthroplasty," Clinical Orthopaedics and Related Research, vol. 466, no. 1, pp. 153-158, 2008.

[22] R. J. Friedman, S. Hess, S. D. Berkowitz, and M. Homering, "Complication rates after hip or knee arthroplasty in morbidly obese patients," Clinical Orthopaedics and Related Research, vol. 471, no. 10, pp. 3358-3366, 2013.

[23] G. Maoz, M. Phillips, J. Bosco et al., “The Otto Aufranc award: modifiable versus nonmodifiable risk factors for infection after hip arthroplasty," Clinical Orthopaedics and Related Research, vol. 473, no. 2, pp. 453-459, 2015.

[24] B. Mraovic, D. Suh, C. Jacovides, and J. Parvizi, "Perioperative hyperglycemia and postoperative infection after lower limb arthroplasty," Journal of Diabetes Science and Technology, vol. 5, no. 2, pp. 412-418, 2011.

[25] L. Pulido, E. Ghanem, A. Joshi, J. J. Purtill, and J. Parvizi, "Periprosthetic joint infection: the incidence, timing, and predisposing factors," Clinical Orthopaedics and Related Research, vol. 466, no. 7, pp. 1710-1715, 2008.

[26] L. Font-Vizcarra, E. Tornero, G. Bori, J. Bosch, J. Mensa, and A. Soriano, "Relationship between intraoperative cultures during hip arthroplasty, obesity, and the risk of early prosthetic joint infection: a prospective study of 428 patients," International Journal of Artificial Organs, vol. 34, no. 9, pp. 870-875, 2011.

[27] V. P. Patel, M. Walsh, B. Sehgal, C. Preston, H. DeWal, and P. E. Di Cesare, "Factors associated with prolonged wound drainage after primary total hip and knee arthroplasty," The Journal of Bone and Joint Surgery - American Volume, vol. 89, no. 1, pp. 3338, 2007.

[28] K. Saleh, M. Olson, S. Resig et al., "Predictors of wound infection in hip and knee joint replacement: results from a 20 year surveillance program," Journal of Orthopaedic Research, vol. 20, no. 3, pp. 506-515, 2002.

[29] M. C. S. Inacio, D. Kritz-Silverstein, R. Raman et al., "The impact of pre-operative weight loss on incidence of surgical site infection and readmission rates after total joint arthroplasty," Journal of Arthroplasty, vol. 29, no. 3, pp. 458.e1-464.el, 2014.

[30] M. E. E. van Kasteren, J. Manniën, A. Ott, B.-J. Kullberg, A. S. de Boer, and I. C. Gyssens, "Antibiotic prophylaxis and the risk of surgical site infections following total hip arthroplasty: timely administration is the most important factor," Clinical Infectious Diseases, vol. 44, no. 7, pp. 921-927, 2007.

[31] K. Lai, E. R. Bohm, C. Burnell, and D. R. Hedden, "Presence of medical comorbidities in patients with infected primary hip or knee arthroplasties," Journal of Arthroplasty, vol. 22, no. 5, pp. 651-656, 2007.

[32] A. A. Rizvi, S. A. Chillag, and K. J. Chillag, "Perioperative management of diabetes and hyperglycemia in patients undergoing orthopaedic surgery," Journal of the American Academy of Orthopaedic Surgeons, vol. 18, no. 7, pp. 426-435, 2010.

[33] M. Turina, D. E. Fry, and H. C. Polk Jr., "Acute hyperglycemia and the innate immune system: clinical, cellular, and molecular aspects," Critical Care Medicine, vol. 33, no. 7, pp. 1624-1633, 2005.

[34] K.-H. Song, E. S. Kim, Y. K. Kim et al., "Differences in the risk factors for surgical site infection between total hip arthroplasty and total knee arthroplasty in the Korean Nosocomial Infections Surveillance System (KONIS)," Infection Control and Hospital Epidemiology, vol. 33, no. 11, pp. 1086-1093, 2012.

[35] R. Iorio, K. M. Williams, A. J. Marcantonio, L. M. Specht, J. F. Tilzey, and W. L. Healy, "Diabetes mellitus, hemoglobin A1C, 
and the incidence of total joint arthroplasty infection," Journal of Arthroplasty, vol. 27, no. 5, pp. 726.el-729.e1, 2012.

[36] M. H. Marchant Jr., N. A. Viens, C. Cook, T. P. Vail, and M. P. Bolognesi, "The impact of glycemic control and diabetes mellitus on perioperative outcomes after total joint arthroplasty," The Journal of Bone and Joint Surgery -American volume, vol. 91, no. 7, pp. 1621-1629, 2009.

[37] T. Bongartz, C. S. Halligan, D. R. Osmon et al., "Incidence and risk factors of prosthetic joint infection after total hip or knee replacement in patients with rheumatoid arthritis," Arthritis Care and Research, vol. 59, no. 12, pp. 1713-1720, 2008.

[38] S. Momohara, K. Kawakami, T. Iwamoto et al., "Prosthetic joint infection after total hip or knee arthroplasty in rheumatoid arthritis patients treated with nonbiologic and biologic diseasemodifying antirheumatic drugs," Modern Rheumatology, vol. 21, no. 5, pp. 469-475, 2011.

[39] M. Gilson, L. Gossec, X. Mariette et al., "Risk factors for total joint arthroplasty infection in patients receiving tumor necrosis factor $\alpha$-blockers: a case-control study," Arthritis Research and Therapy, vol. 12, no. 4, article R145, 2010.

[40] K. Kawakami, K. Ikari, K. Kawamura et al., "Complications and features after joint surgery in rheumatoid arthritis patients treated with tumour necrosis factor- $\alpha$ blockers: perioperative interruption of tumour necrosis factor-a blockers decreases complications?” Rheumatology, vol. 49, no. 2, Article ID kep376, pp. 341-347, 2010.

[41] A. Ruyssen-Witrand, L. Gossec, C. Salliot et al., "Complication rates of 127 surgical procedures performed in rheumatic patients receiving tumor necrosis factor alpha blockers," Clinical and Experimental Rheumatology, vol. 25, no. 3, pp. 430-436, 2007.

[42] E. F. Berbari, A. D. Hanssen, M. C. Duffy et al., "Risk factors for prosthetic joint infection: case-control study," Clinical Infectious Diseases, vol. 27, no. 5, pp. 1247-1254, 1998.

[43] S. L. Jiang, W. W. Schairer, and K. J. Bozic, "Increased rates of periprosthetic joint infection in patients with cirrhosis undergoing total joint arthroplasty," Clinical Orthopaedics and Related Research, vol. 472, no. 8, pp. 2483-2491, 2014.

[44] A. J. Reiffel, P. S. Barie, and J. A. Spector, "A multi-disciplinary review of the potential association between closed-suction drains and surgical site infection," Surgical Infections, vol. 14, no. 3, pp. 244-269, 2013.

[45] S. M. Jafari, D. S. Casper, C. Restrepo, B. Zmistowski, J. Parvizi, and P. F. Sharkey, "Periprosthetic joint infection: are patients with multiple prosthetic joints at risk?" Journal of Arthroplasty, vol. 27, no. 6, pp. 877-880, 2012.

[46] E. Fulkerson, C. J. della Valle, B. Wise, M. Walsh, C. Preston, and P. E. di Cesare, "Antibiotic susceptibility of bacteria infecting total joint arthroplasty sites," The Journal of Bone and Joint Surgery. American Volume, vol. 88, no. 6, pp. 1231-1237, 2006.

[47] D. M. LaPorte, B. J. Waldman, M. A. Mont, and D. S. Hungerford, "Infections associated with dental procedures in total hip arthroplasty," The Journal of Bone and Joint Surgery-British Volume, vol. 81, no. 1, pp. 56-59, 1999.

[48] L. A. Poultsides, L. K. Papatheodorou, T. S. Karachalios et al., "Novel model for studying hematogenous infection in an experimental setting of implant-related infection by a community-acquired methicillin-resistant $S$. aureus strain," Journal of Orthopaedic Research, vol. 26, no. 10, pp. 1355-1362, 2008.
[49] R. Sousa, E. Muñoz-Mahamud, J. Quayle et al., "Is asymptomatic bacteriuria a risk factor for prosthetic joint infection?" Clinical Infectious Diseases, vol. 59, no. 1, pp. 41-47, 2014.

[50] J. S. Everhart, E. Altneu, and J. H. Calhoun, "Medical comorbidities are independent preoperative risk factors for surgical infection after total joint arthroplasty," Clinical Orthopaedics and Related Research, vol. 471, no. 10, pp. 3112-3119, 2013.

[51] E. Murphy, S. J. Spencer, D. Young, B. Jones, and M. J. G. Blyth, "MRSA colonisation and subsequent risk of infection despite effective eradication in orthopaedic elective surgery," Journal of Bone and Joint Surgery -British Volume, vol. 93, no. 4, pp. 548551, 2011.

[52] D. H. Kim, M. Spencer, S. M. Davidson et al., "Institutional prescreening for detection and eradication of methicillinresistant Staphylococcus aureus in patients undergoing elective orthopaedic surgery," The Journal of Bone and Joint SurgeryAmerican Volume, vol. 92, no. 9, pp. 1820-1826, 2010.

[53] E. B. Smith, R. Wynne, A. Joshi, H. Liu, and R. P. Good, "Is it time to include vancomycin for routine perioperative antibiotic prophylaxis in total joint arthroplasty patients?" The Journal of Arthroplasty, vol. 27, no. 8, supplement, pp. 55-60, 2012.

[54] P. Innerhofer, A. Klingler, C. Klimmer, D. Fries, and W. Nussbaumer, "Risk for postoperative infection after transfusion of white blood cell-filtered allogeneic or autologous blood components in orthopedic patients undergoing primary arthroplasty," Transfusion, vol. 45, no. 1, pp. 103-110, 2005.

[55] E. T. Newman, T. S. Watters, J. S. Lewis et al., "Impact of perioperative allogeneic and autologous blood transfusion on acute wound infection following total knee and total hip arthroplasty," The Journal of Bone and Joint Surgery Series A, vol. 96, no. 4, pp. 279-284, 2014.

[56] W. H. Dzik, "Leukoreduction of blood components," Current Opinion in Hematology, vol. 9, no. 6, pp. 521-526, 2002.

[57] S. G. Memtsoudis, X. Sun, Y. L. Chiu et al., "Perioperative comparative effectiveness of anesthetic technique in orthopedic patients," Anesthesiology, vol. 118, no. 5, pp. 1046-1058, 2013.

[58] J. H. Park, M. R. Rasouli, S. M. J. Mortazavi, A. T. Tokarski, M. G. Maltenfort, and J. Parvizi, "Predictors of perioperative blood loss in total joint arthroplasty," The Journal of Bone and Joint Surgery-American Volume, vol. 95, no. 19, pp. 1777-1783, 2013.

[59] C. J. McDougall, H. S. Gray, P. M. Simpson, S. L. Whitehouse, R. W. Crawford, and W. J. Donnelly, "Complications related to therapeutic anticoagulation in total hip arthroplasty," The Journal of Arthroplasty, vol. 28, no. 1, pp. 187-192, 2013.

[60] J. Parvizi, E. Ghanem, A. Joshi, P. F. Sharkey, W. J. Hozack, and R. H. Rothman, "Does "excessive" anticoagulation predispose to periprosthetic infection?" Journal of Arthroplasty, vol. 22, no. 6, supplement 2, pp. 24-28, 2007.

[61] J. Parvizi, T. Gehrke, and A. F. Chen, "Proceedings of the international consensus on periprosthetic joint infection," Bone and Joint Journal, vol. 95, no. 11, pp. 1450-1452, 2013.

[62] R. O. Darouiche, M. J. Wall Jr., K. M. F. Itani et al., "Chlorhexidine-alcohol versus povidone-iodine for surgicalsite antisepsis," The New England Journal of Medicine, vol. 362, no. 1, pp. 18-26, 2010.

[63] K. J. Bozic, K. Ong, E. Lau et al., "Risk of complication and revision total hip arthroplasty among medicare patients with different bearing surfaces," Clinical Orthopaedics and Related Research, vol. 468, no. 9, pp. 2357-2362, 2010.

[64] M. E. Berend, M. A. Ritter, L. D. Harty et al., "Simultaneous bilateral versus unilateral total hip arthroplasty: an outcomes 
analysis," Journal of Arthroplasty, vol. 20, no. 4, pp. 421-426, 2005.

[65] E. Tsiridis, G. Pavlou, J. Charity, G. Gie, and R. West, “The safety and efficacy of bilateral simultaneous total hip replacement: an analysis of 2063 cases," The Journal of Bone and Joint SurgeryBritish Volume, vol. 90, no. 8, pp. 1005-1012, 2008.

[66] J. Liu, C. Ma, N. Elkassabany, L. A. Fleisher, and M. D. Neuman, "Neuraxial anesthesia decreases postoperative systemic infection risk compared with general anesthesia in knee arthroplasty," Anesthesia and Analgesia, vol. 117, no. 4, pp. 10101016, 2013.

[67] A. J. Pugely, C. T. Martin, Y. Gao, S. Mendoza-Lattes, and J. J. Callaghan, "Differences in short-term complications between spinal and general anesthesia for primary total knee arthroplasty," The Journal of Bone and Joint Surgery. American Volume, vol. 95, no. 3, pp. 193-199, 2013.

[68] F. Hovaguimian, C. Lysakowski, N. Elia, and M. R. Tramèr, "Effect of intraoperative high inspired oxygen fraction on surgical site infection, postoperative nausea and vomiting, and pulmonary function: systematic review and meta-analysis of randomized controlled trials," Anesthesiology, vol. 119, no. 2, pp. 303-316, 2013.

[69] E. L. P. E. Geubbels, J. C. Wille, N. J. D. Nagelkerke, C. M. J. E. Vandenbroucke-Grauls, D. E. Grobbee, and A. S. de Boer, "Hospital-related determinants for surgical-site infection following hip arthroplasty," Infection Control and Hospital Epidemiology, vol. 26, no. 5, pp. 435-441, 2005.

[70] J. N. Katz, N. N. Mahomed, J. A. Baron et al., "Association of hospital and surgeon procedure volume with patient-centered outcomes of total knee replacement in a population-based cohort of patients age 65 years and older," Arthritis and Rheumatism, vol. 56, no. 2, pp. 568-574, 2007.

[71] J. Muilwijk, S. van den Hof, and J. C. Wille, "Associations between surgical site infection risk and hospital operation volume and surgeon operation volume among hospitals in the Dutch nosocomial infection surveillance network," Infection Control and Hospital Epidemiology, vol. 28, no. 5, pp. 557-563, 2007.

[72] J. Lee, R. Singletary, K. Schmader, D. J. Anderson, M. Bolognesi, and K. S. Kaye, "Surgical site infection in the elderly following orthopaedic surgery: risk factors and outcomes," The Journal of Bone and Joint Surgery. American Volume, vol. 88, no. 8, pp. 1705-1712, 2006. 


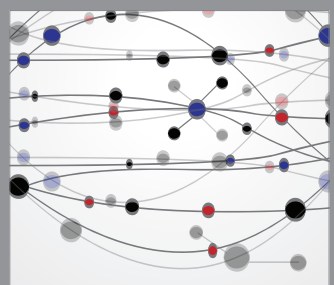

The Scientific World Journal
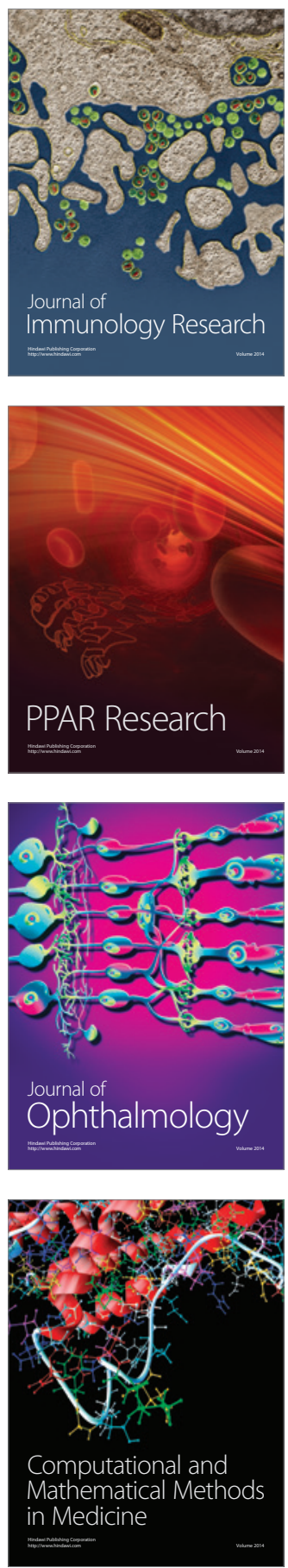

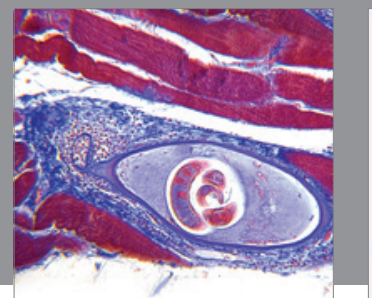

Gastroenterology

Research and Practice
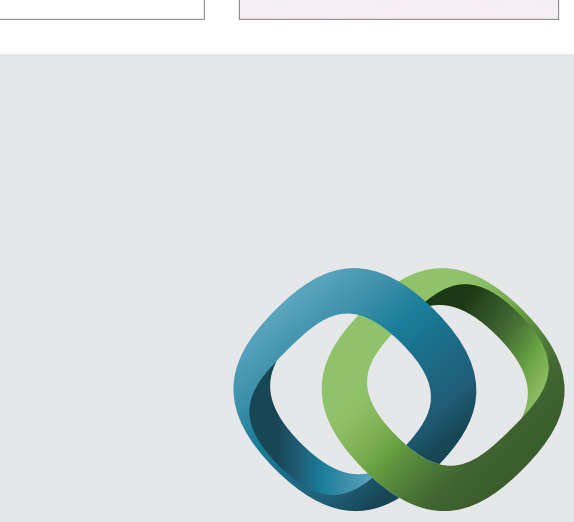

\section{Hindawi}

Submit your manuscripts at

http://www.hindawi.com
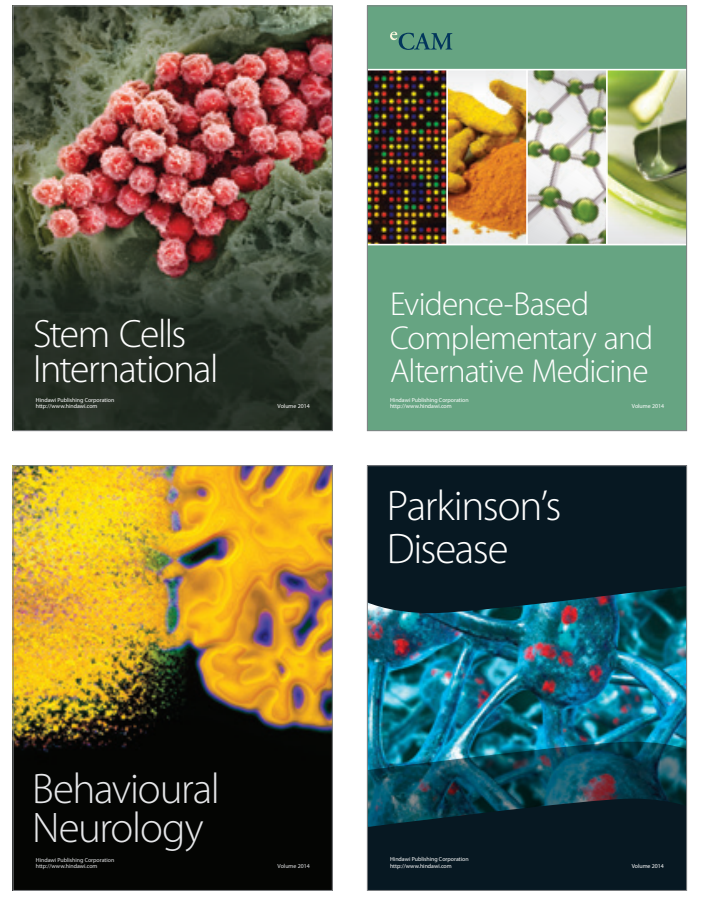
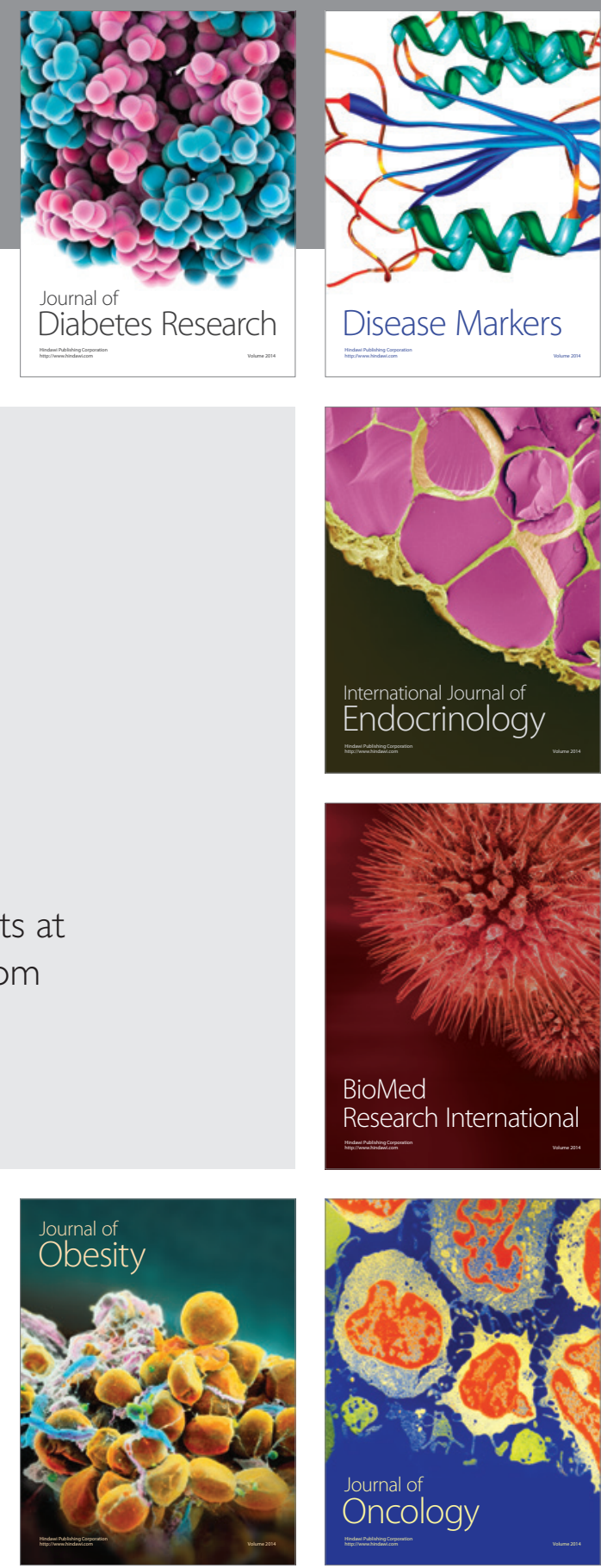

Disease Markers
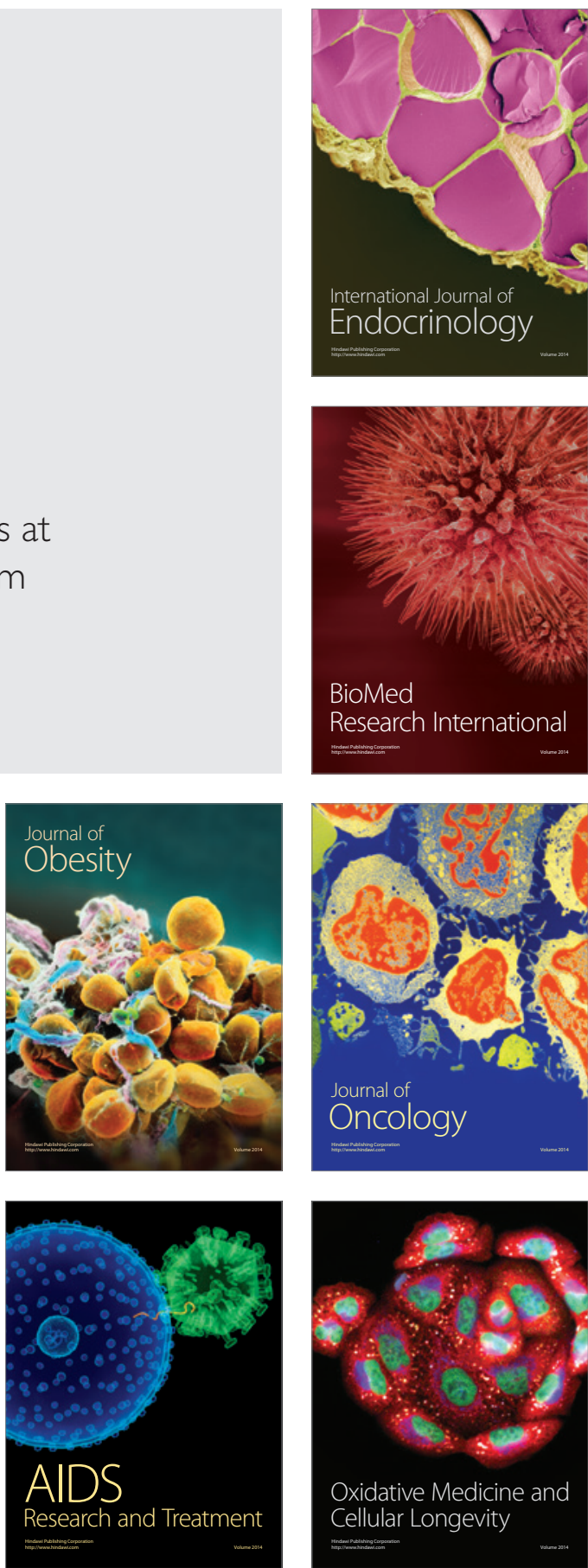